\title{
Comparison of Craniometric Features between Domestic Pig (Sus scrofa forma domestica) and Wild Boar (Sus scrofa) from Transylvania Region
}

\author{
Radu CONSTANTINESCU, Viorica COŞIER, Daniel COCAN, Vioara MIREŞAN* \\ University of Agricultural Sciences and Veterinary Medicine, Faculty of Animal Science and \\ Biotechnologies, 3-5 Mănăştur Street, 400372 Cluj-Napoca, Romania \\ *Corresponding author, email: vmiresan@yahoo.com
}

Bulletin UASVM Animal Science and Biotechnologies 71(2) / 2014,

Print ISSN 1843-5262; Electronic ISSN 1843-536X

DOI:10.15835/buasvmcn-asb:10833

\begin{abstract}
Pigs were among the first domesticated animal species after dog, sheep and goats, this important step for mankind dating from late Paleolithic and early Neolithic. Thus current forms of domestic swine are based on wild pigs, the most representative of them are the Asian wild boar and European wild boar. This statement is supported by the fact that the forms of domestic pigs and wild boars can carry interspecific crosses, resulting fruitful hybrids. Based on these arguments take shape the purpose of this scientific papers, to make a comparison between the skull bones of the wild boar and domestic pig, as a result of different environmental conditions in which they formed, they lived and were consolidated during phylogenetic evolution in Transylvania region. For this purpouse 52 craniometric measurements were carried to 20 individuals adult males over the age of 4 years, 10 males of wild boar and 10 males of domestic pig specimens belonging to indigenous breeds of pigs. Further processing of data (GraphPad Prism 6) revealed the existence of significant and highly significant differences between craniometric features of wild boar and domestic pigs.
\end{abstract}

Keywords: craniometric features, domestic pig, wild boars

\section{INTRODUCTION}

Due to the high adaptive abilities of the representatives of the Suidae family, they are widespread all over the world. According to Oliver et al. (1993), the species Sus Scrofa is the most numerous representative of suborder nonruminants (Suiformes) and the most widely spread species of the Suidae family (Doychev et al., 2012). Pigs were among the first domesticated animal species after dog, sheep and goats, this important step for mankind dating from late Paleolithic and early Neolithic. The earliest evidence of pigs were found in South East of Anatolia, in the Cayönü region, and have been dated from the year 7000 B.C. Studies conducted in recent years in the sequences of mtDNA, showed that pig domestication occurred independently in several geographic areas of Eurasia. Wild ancestor of the domestic pig is the wild boar (Sus scrofa), who inhabit in most forest of Romania, in the Danube Delta and in the bushes of the Carpathians mountains. The morphological structure and craniometric features of skulls in different mammalian species is described in many papers in the literature (Brudnicki, 2005). Data on craniometric features in representatives of Suidae can be found in the monograph of the wild boar, reported by Kozlo (1975), while Obrez (1996) analyzed some craniometric features in miniature pigs. Thus current forms of domestic swine are based on wild pigs, the most representative of them are Asian wild boar and European wild boar. This statement is supported by the fact that the forms of domestic pigs and wild boars can carry interspecific crosses, resulting fruitful hybrids.

Based on these arguments take shape the purpose of this scientific papers, to make a comparison between the skull bones of the wild boar and domestic pig, as a result of different 
environmental conditions in which they formed, they lived and were consolidated during phylogenetic evolution in Transylvania region.

\section{MATERIALS AND METHODS}

The skulls of 20 male, 10 domestic local breeds pig and 10 wild boars hunting trophies from Brașov and Cluj counties, all in completed growth, were used as biological material for the present study. The age of the specimens was determined on the basis of the stage of growth of the third molar tooth (M3). That molar is completely developed at the age of four years (Genov et al., 1992; 1999). After the fourth year, the size of the skull remains largely unchanged (Kozlo, 1975); therefore, only specimens four years and older were included in the analyses.

The animal skulls were macerated by cooking, and then muscles and the cerebrum were mechanically removed and immersed into 5\% hydrogen peroxide for bleaching. Craniometric measurements were taken following the methodology of Von den Driesch (1976), a total of 52 skulls craniometric features. Measurements were made using the following tools: electronic caliper, zootechnical dividers and calibrated ruler (accuracy $0.01 \mathrm{~mm}$ and a ruler $-1 \mathrm{~mm}$ ).

The following points were defined in the skulls: Prosthion (P), Rhinion (Rh), Naso-incisive incision (Ini), Infraorbital hole (Inf), Nasion (N), Supraorbital(Sp), Entorbital (Ent), Ectorbital (Ect), Zygion (Zy), Bregma (Br), Akrokranion $(\mathrm{Ak})$, Opisthocranion (Op), Basion (Ba), Hornion $(\mathrm{H})$, Staphylion (St), Postdental (Pd), Premolar (Pm), Molar 3 (M3), Premolar 1 (P1), Premolar 2 (P2), Canine recess (C), Incisive 3 (I3), Nasointermaxillare (Ni), Otion (Ot), Opisthion (O).

After being marked the points the following measurements were taken for each skull on the dorsal (Fig. 1), ventral (Fig. 2), lateral (Fig 3), aboral (Fig. 4) view and also on the mandible bone (Fig. 5).

On dorsal view of the skulls we conducted a total of 16 craniometric measurements as follows:

1. Prosthion- Akrokranion (P-Ak) skull length

2. Prosthion- Opisthocranion (P-Op) profile length

3. Akrokranion- Nasion (Ak-N) neurocranium dorsal length

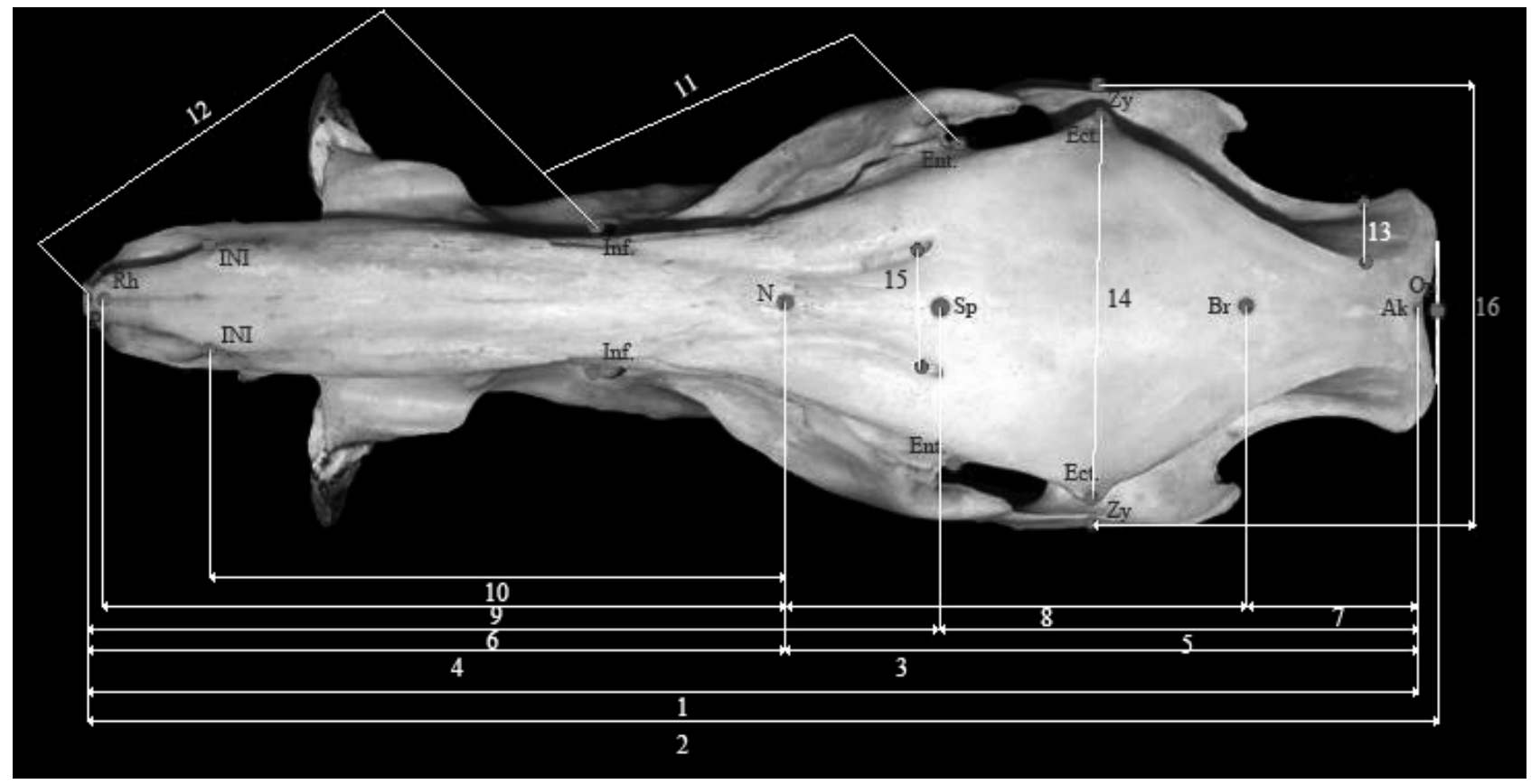

Fig. 1. Dorsal view of the wild boar skull. 1 -Skull length; 2 -Profile length; 3 -Neurocranium dorsal length; 4 - Viscerocranium length; 5 -Higher neurocranium length; 6 -Face length; 7 -Parietal bone length; 8 -Length of frontal bone; 9 -Maximum length of nasal bone; 10 -Minimum length of the nasal bone; 11 -Ent- Infraorbital hole length; 12 -Infraorbital hole - P length; 13 -The minimum width of parietal bone; 14 -The maximum width of the frontal bone; 15 -Width between supraorbital holes; 16 -The maximum width of the skull. 
4. Nasion- Prosthion (N-P) viscerocranium length

5. Akrokranion- Supraorbital (Ak-Sp) higher neurocranium length

6. Supraorbital- Prosthion (Sp-P) face length

7. Akrokranion- Bregma (Ak-Br) parietal bone length

8. Bregma- Nasion (Br-N) length of frontal bone

9. Nasion- Rhinion (N-Rh) maximum length of nasal bone

10. Naso-incisive incision- Nasion (Ini-N) minimum length of nasal bone
11. Entorbital- Naso-incisive incision (Ent-Inf) entorbital- infraorbital hole length

12. Naso-incisive incision- Prosthion (Inf-P) infraorbital hole - prosthion length

13. The minimum width of parietal bone

14. Ectorbital- Ectorbital (Ect-Ect) the maximum width of the frontal bone

15. Width between supraorbital holes

16. Zygion- Zygion (Zy-Zy) the maximum width of the skull

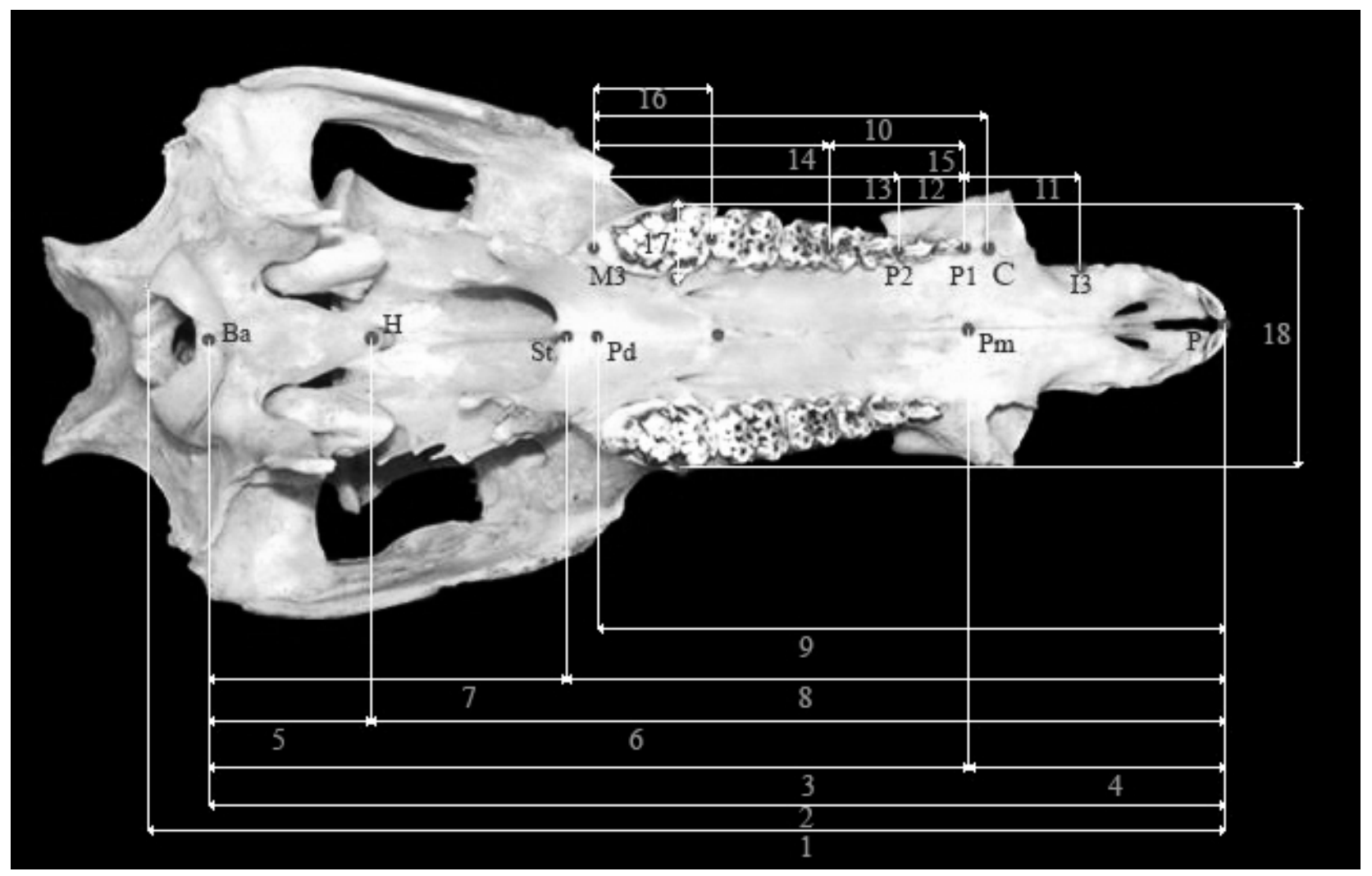

Fig. 2. Ventral view of wild boar skull. 1 -Condylo - basal length; 2 -Basal length; 3 -Occipital Length-Palatine incisive apophyses; 4 -Palatine apophyses of incisive bone length; 5 -Basioccipital length; 6 -Axis basi - facial length; 7 -Condyle - palatine length; 8 -Palate length; 9 -The length of the upper dental arch; 10 -Pd-Canine recess length; 11 -Diastema length; 12 -Premolaro-molar length; 13 -Molar 3 -Premolar2 Length; 14 - Molar length; 15

-Premolar length; 16 -Length of third molar; 17 -Width of third molar; 18 -Maximum width of the hard palate.

On ventral view of the skulls we conducted a total of 18 craniometric measurements as follows:

1. Occipital condyle- Prosthion (Condyl-P) condylo - basal length

2. Basion- Prosthion (Ba-P) basal length

3. Basion- Premolar (Ba-Pm) occipital bone -palatine incisive apophyses length
4. Premolar- Prosthion (Pm-P) palatine apophyses of incisive bone length

5. Basion- Hornion (Ba-H) basioccipital length

6. Hornion- Prosthion (H-P) axis basi - facial length

7. Basion- Staphylion (Ba-St) Condyle - palatine length

8. Staphylion- Prosthion (St-P) palatine length 
9. Postdental- Prosthion (Pd-P) the length of the upper dental arch

10. Molar 3-Canine recess (M3-C) molar 3- canine recess length

11. Incisive 3-Premolar 1 (I3-P1) diastema length

12. Premolar 1- Molar 3 (P1-M3) premolaromolar length
13. Molar 3- Premolar 1 (M3-P2) molar 3 - premolar2 length

14. Molar length

15. Premolar length

16. Length of third molar

17. Width of third molar

18. Maximum width of the hard palate

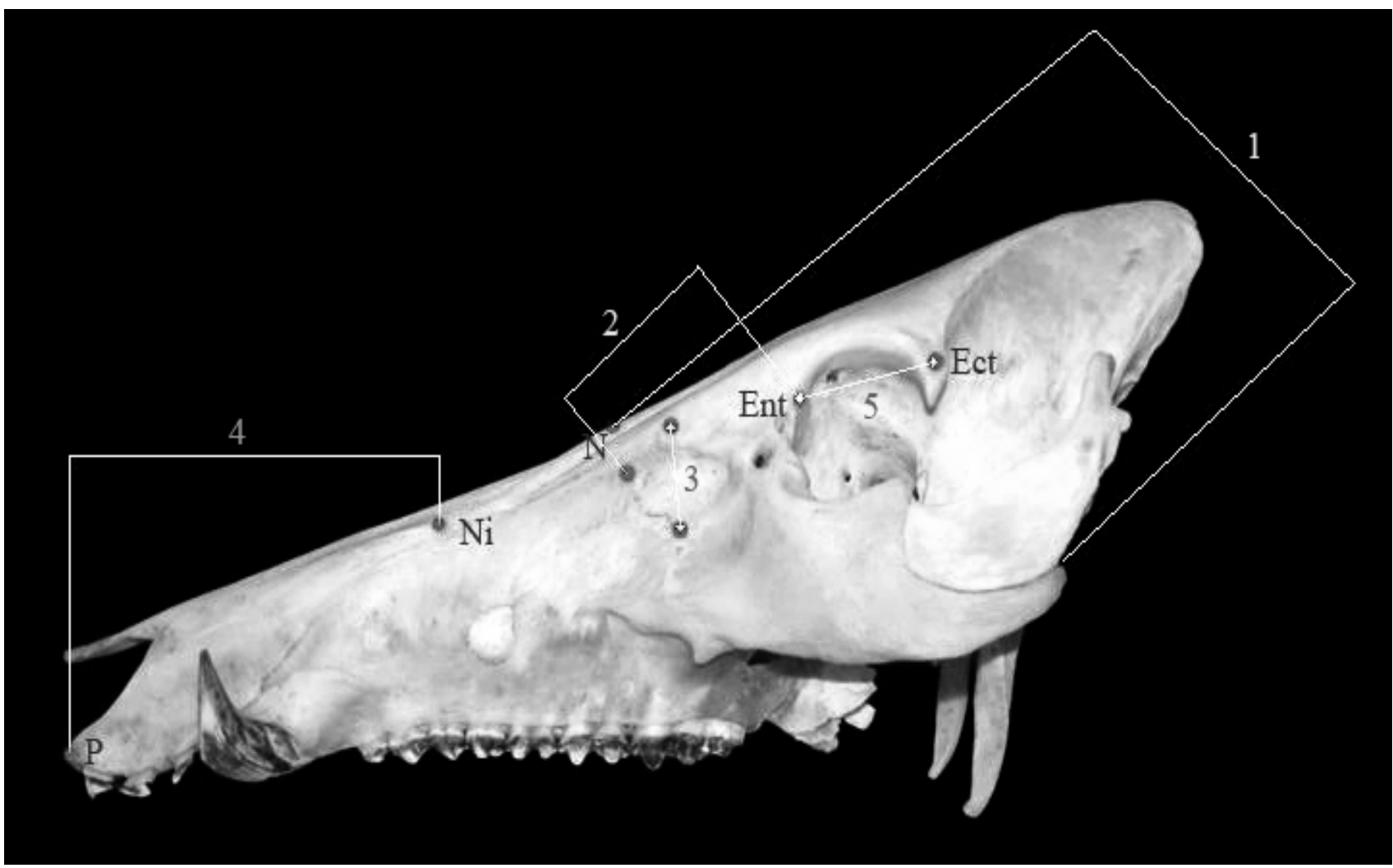

Fig. 3. Lateral view of wild boar skull. 1 -Maximum length of neurocranium; 2 -Length of the lacrimal bones; 3 -Height of the lacrimal bones; 4 -Lateral length of premaxilla; 5 -Ect-Ent length.

On lateral view of the skulls we conducted a total of 5 craniometric measurements as follows:

1. Basion- Nasion (Ba-N) maximum length of neurocranium

2. Length of the lacrimal bones

3. Height of the lacrimal bones

4. Nasointermaxillare- Prosthion (Ni-P) lateral length of premaxilla

5. Ectorbital- Entorbital (Ect-Ent ) ectorbitalentorbital length
On aboral view of the skulls we conducted a total of 8 craniometric measurements as follows:

1. Otion- Otion (Ot-Ot) external auditory canals distance

2. Occipital condyle width

3. Width of jugular apophysis

4. Width of occipital hole

5. Opisthion- Basion (O-Ba) height of occipital hole

6. Maximum width of nuchal crests

7. Minimum width of nuchal crests

8. Basion- Akrokranion (Ba-Ak) aboral height of neurocranium 


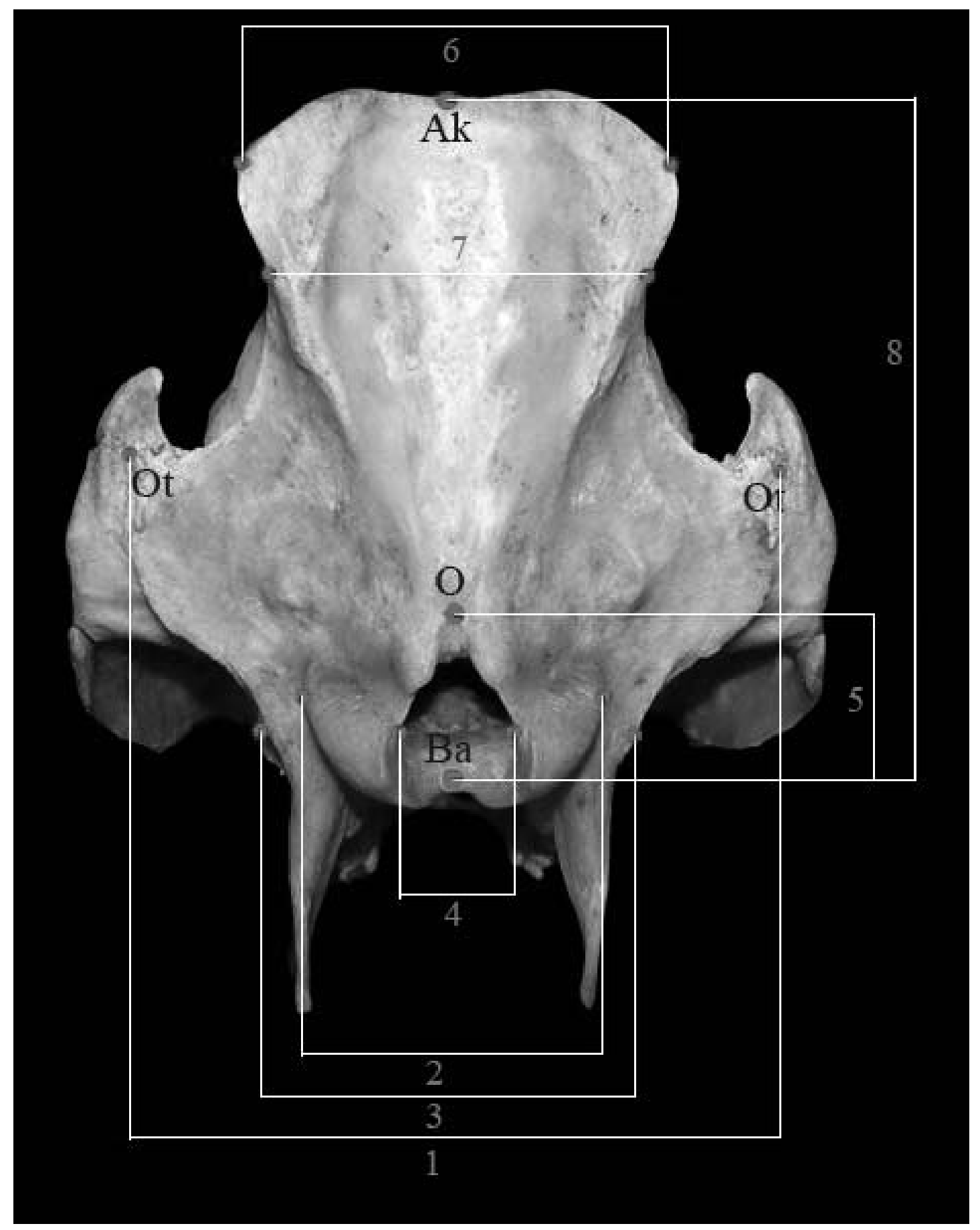

Fig. 4. Aboral view of wild boar skull. 1 -External auditory canals distance; 2 -Occipital condyle width; 3 -Width of jugular apophysis; 4 -Width of occipital hole; 5 -Height of occipital hole;

6 -Maximum width of nuchal crests; 7 -Minimum width of nuchal crests; 8 -Aboral height of neurocranium

Also we conducted 5 craniometric measurements regarding the mandible bone as follows:

1. Length of mandible

2. Height of mandible

3. Width of mandible branches
4. Length of upper canines

5. Length of lower canines

The results of the study was statistically processed using bio-informatic program Graphpad Prism v.6.04. 


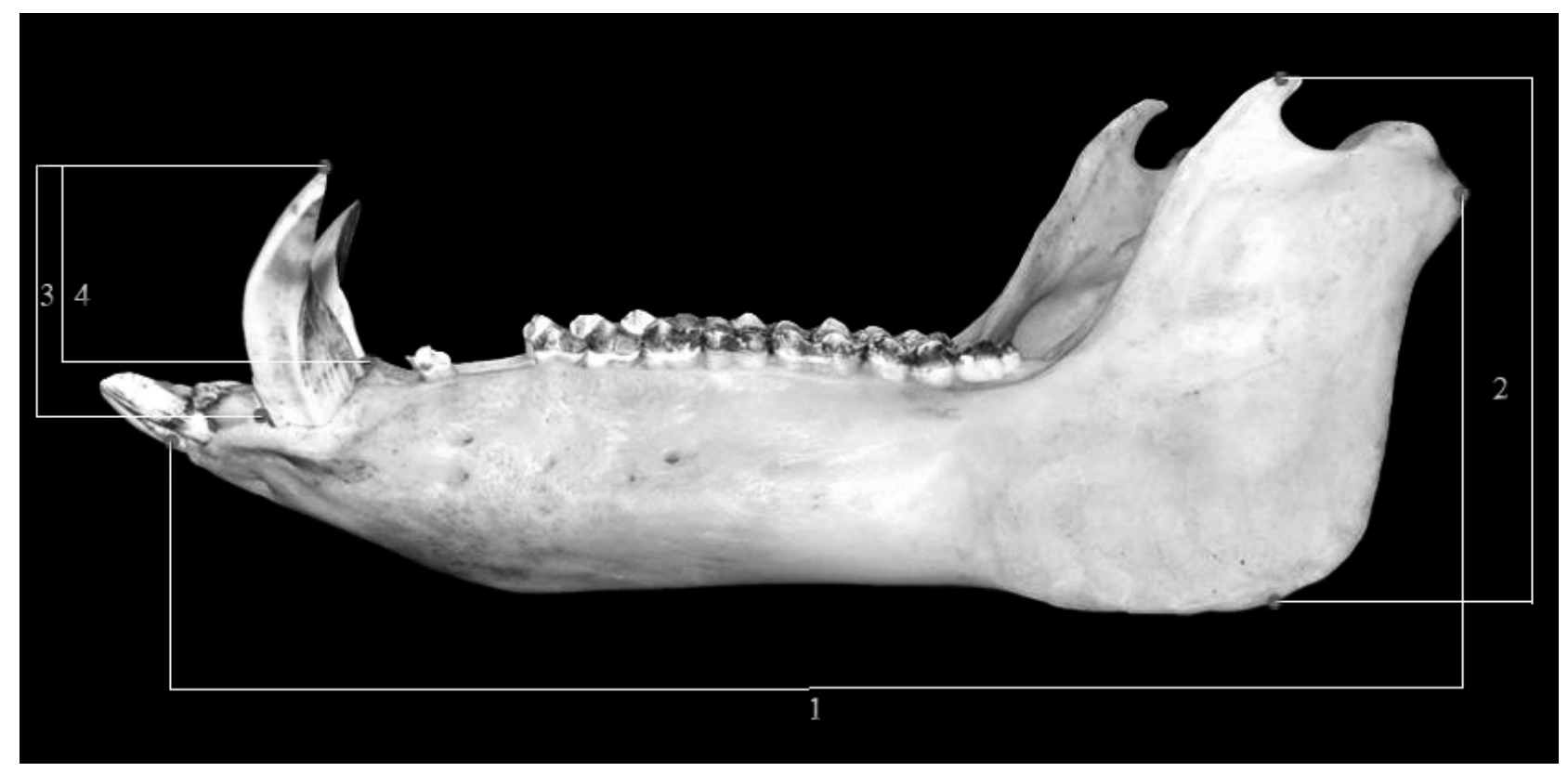

Fig. 5. Mandible of wild boar. 1 -Length of mandible; 2 -Height of mandible;

3 -Width of mandible branches; 4 -Length of upper canines; 5 -Length of lower canines

\section{RESULTS AND DISCUSSION}

The variability of craniometric indices regarding wild boar is between a minimum of $0.68 \%$ if the length of the side of the premaxilla and a maximum of $23.81 \%$ for occipitalbase length . Domestic pig craniometric indices variability ranges between a minimum of $0.40 \%$ in the length of the jaw and a maximum of $35.42 \%$ in the parietal bone length.

Regarding the significance of differences for mean values of wild boar and domestic pig from all the 52 indicators considered in this study there were a total of 19 values of the means statistically insignificant. Thus insignificant statistically values was recorded for parietal bone length, the minimum width of parietal bone, width between supraorbital holes, condylo-basal length, basal length,occipital length-palatine incisiveapophyses, basioccipital length, condyle-palatine length, palate length, Pd-Canine recess length, diastema length, premolar length, length of third molar, width of third molar, maximum width of the hard palate, maximum length of neurocranium, height of the lacrimal bones, Ect-Ent length and width of occipital hole. Also in the case of 14 craniometric indices were recorded differences statistically highly significant. Of these indices in the case of 10 craniometric measurments (viscerocranium length, face length, maximum length of nasal bone, Ent-infraorbital hole length, length of the lacrimal bones, lateral length of premaxilla, height of occipital hole, length of mandible, length of upper canines, length of lower canines) the differences are in favor of wild boar, and for the other 4 craniometric indices (the maximum width of the skull, maximum width of nuchal crests, minimum width of nuchal crests, width of mandible branches) the statistical differences are in the favor of domestic pig (Tab. 1).

Regarding the differences statistically significant they were recorded in 8 of the 52 indicators included in this study. This craniometric indices are: palatine apophyses of incisive bone length, axis basi-facial length, the length of the upper dental arch, molar 3 -premolar 2 length, molar length, occipital condyle width, width of jugular apophysis and aboral height of neurocranium.

Differences statistical significantly distinct between the means of the wild boars and domestic pig was found only in the case of 3 craniometric measurments (higher neurocranium length, premolaro-molar length and neurocranium dorsal length) and in the favor of wild boar. Regarding the differences statistically very significant they were recorded in 8 of the 52 indicators included in this study. Thus statistically very significant values was 
Tab. 1. Mean values, variability and significance of differences ( $t$ test) of craniometric features in Suidae from Transylvania region

\begin{tabular}{|c|c|c|c|c|c|c|c|}
\hline \multirow{2}{*}{$\begin{array}{l}\text { Crt. } \\
\text { nr. }\end{array}$} & \multirow{2}{*}{ Craniometric features } & \multicolumn{2}{|c|}{ Wild boar } & \multicolumn{2}{|c|}{ Domestic pigs } & \multirow{2}{*}{ D } & \multirow{2}{*}{$\begin{array}{l}\mathrm{t} \text { test / } \\
\text { test }(\mathrm{P}) \\
\end{array}$} \\
\hline & & $\mathrm{X} \pm \mathrm{s}_{\mathrm{x}}$ & $\mathrm{V} \%$ & $\mathrm{X} \pm \mathrm{sx}$ & $\mathrm{V} \%$ & & \\
\hline 1 & Skull length & $409.8 \pm 5.490$ & 3 & $314.8 \pm 13.09$ & 9.30 & $6.694 * * *$ & 0.0009 \\
\hline 2 & Profile length & $426.3 \pm 2.154$ & 1.13 & $327.8 \pm 10.85$ & 7.40 & $8.904 * * *$ & 0.0006 \\
\hline 3 & Neurocranium dorsal length & $198.3 \pm 3.929$ & 4.43 & $142.3 \pm 9.287$ & 14.59 & $5.554 * *$ & 0.0020 \\
\hline 4 & Viscerocranium length & $211.3 \pm 0.8602$ & 0.91 & $165.3 \pm 1.281$ & 1.73 & $29.82 * * * *$ & $<0.0001$ \\
\hline 5 & Higher neurocranium length & $155.3 \pm 1.715$ & 2.47 & $111.8 \pm 9.063$ & 18.13 & $4.716 * *$ & 0.0078 \\
\hline 6 & Face length & $256.3 \pm 2.596$ & 2.26 & $194.8 \pm 1.068$ & 1.23 & $21.91 * * * *$ & $<0.0001$ \\
\hline 7 & Parietal bone length & $62.76 \pm 0.5008$ & 1.78 & $45.10 \pm 7.144$ & 35.42 & $2.466 \mathrm{~ns}$ & 0.0686 \\
\hline 8 & Length of frontal bone & $132.5 \pm 3.742$ & 6.32 & $96.40 \pm 1.897$ & 4.40 & $8.593 * * *$ & 0.0001 \\
\hline 9 & Maximum length of nasal bone & $207.8 \pm 1.497$ & 1.61 & $162.8 \pm 2.818$ & 3.87 & $14.10 * * * *$ & $<0.0001$ \\
\hline 10 & Minimum length of the nasal bone & $168.3 \pm 3.929$ & 5.22 & $127.5 \pm 1.610$ & 2.82 & $9.615 * * *$ & 0.0001 \\
\hline 11 & Ent- Infraorbital hole length & $109.1 \pm 4.297$ & 8.81 & $67.76 \pm 3.420$ & 11.29 & $7.528 * * * *$ & $<0.0001$ \\
\hline 12 & Infraorbital hole - P length & $164.3 \pm 1.281$ & 1.74 & $152.8 \pm 0.663$ & 0.97 & $7.979 * * *$ & 0.0002 \\
\hline 13 & The minimum width of parietal bone & $24.84 \pm 0.8480$ & 7.63 & $23.92 \pm 0.397$ & 3.71 & $0.9823 \mathrm{~ns}$ & 0.3659 \\
\hline 14 & The maximum width of the frontal bone & $119.7 \pm 2.2 .322$ & 4.34 & $136.3 \pm 2.015$ & 3.31 & $5.411 * * *$ & 0.0007 \\
\hline 15 & Width between supraorbital holes & $34.13 \pm 0.4226$ & 2.77 & $33.20 \pm 1.769$ & 11.92 & $0.5112 \mathrm{~ns}$ & 0.6335 \\
\hline 16 & The maximum width of the skull & $161.8 \pm 0.3742$ & 0.52 & $197.8 \pm 2.375$ & 2.68 & $14.97 * * * *$ & $<0.0001$ \\
\hline 17 & Condylo - basal length & $357.3 \pm 0.8602$ & 0.54 & $343.3 \pm 6.160$ & 4.01 & $2.251 \mathrm{~ns}$ & 0.0850 \\
\hline 18 & Basal length & $344.3 \pm 1.281$ & 0.83 & $327.3 \pm 7.053$ & 4.82 & $2.372 \mathrm{~ns}$ & 0.0727 \\
\hline 19 & Occipital Length-Palatine incisive apophyses & $239.8 \pm 0.3742$ & 0.35 & $226.6 \pm 6.383$ & 6.29 & $2.033 \mathrm{~ns}$ & 0.113 \\
\hline 20 & Palatine apophyses of incisive bone length & $109.7 \pm 3.464$ & 7.06 & $97.53 \pm 1.399$ & 3.21 & $3.265 *$ & 0.0207 \\
\hline 21 & Basioccipital length & $43.76 \pm 4.660$ & 23.8 & $51.93 \pm 2.134$ & 9.19 & $1.593 \mathrm{~ns}$ & 0.1657 \\
\hline 22 & Axis basi - facial length & $301.3 \pm 6.606$ & 4.90 & $275.8 \pm 3.262$ & 2.64 & $3.461 *$ & 0.0140 \\
\hline 23 & Condyle - palatine length & $99.26 \pm 2.029$ & 4.57 & $95.88 \pm 2.059$ & 4.80 & $1.169 \mathrm{~ns}$ & 0.2759 \\
\hline 24 & Palate length & $245.8 \pm 4.598$ & 4.18 & $237.8 \pm 3.707$ & 3.49 & $1.355 \mathrm{~ns}$ & 0.2142 \\
\hline 25 & The length of the upper dental arch & $234.8 \pm 3.707$ & 3.53 & $221.3 \pm 1.715$ & 1.73 & $3.305 *$ & 0.0179 \\
\hline 26 & Pd- Canine recess length & $141.2 \pm 3.533$ & 5.60 & $141.6 \pm 1.571$ & 2.48 & $0.1138 \mathrm{~ns}$ & 0.9134 \\
\hline 27 & Diastema length & $54.60 \pm 0.9176$ & 3.76 & $51.69 \pm 1.257$ & 5.44 & $1.872 \mathrm{~ns}$ & 0.1015 \\
\hline 28 & Premolaro-molar length & $129.1 \pm 1.987$ & 3.44 & $116.5 \pm 2.483$ & 4.77 & $3.963 * *$ & 0.0046 \\
\hline 29 & Molar 3 -Premolar2 Length & $118.4 \pm 1.778$ & 3.36 & $109.3 \pm 2.909$ & 5.95 & $2.678 *$ & 0.0333 \\
\hline 30 & Molar length & $76.03 \pm 1.003$ & 2.95 & $69.01 \pm 2.357$ & 7.64 & $2.739 *$ & 0.0377 \\
\hline 31 & Premolar length & $52.23 \pm 0.6409$ & 2.74 & $48.92 \pm 2.020$ & 9.23 & $1.564 \mathrm{~ns}$ & 0.1810 \\
\hline 32 & Length of third molar & $36.28 \pm 0.7130$ & 4.39 & $36.19 \pm 0.892$ & 5.52 & $0.0787 \mathrm{~ns}$ & 0.9392 \\
\hline 33 & Width of third molar & $28.88 \pm 0.5314$ & 5.43 & $22.08 \pm 0.722$ & 7.32 & $0.2185 \mathrm{~ns}$ & 0.8330 \\
\hline 34 & Maximum width of the hard palate & $82.35 \pm 1.242$ & 3.37 & $82.61 \pm 1.085$ & 2.94 & $0.1577 \mathrm{~ns}$ & 0.8787 \\
\hline 35 & Maximum length of neurocranium & $251.3 \pm 7.053$ & 6.28 & $241.8 \pm 5.490$ & 5.08 & $1.063 \mathrm{~ns}$ & 0.3206 \\
\hline 36 & Length of the lacrimal bones & $58.05 \pm 0.95$ & 4.22 & $32.15 \pm 0.669$ & 4.65 & $20.18 * * * *$ & $<0.0001$ \\
\hline 37 & Height of the lacrimal bones & $31.94 \pm 0.4885$ & 3.42 & $30.04 \pm 1.414$ & 10.53 & $1.267 \mathrm{~ns}$ & 0.2615 \\
\hline 38 & Lateral length of premaxilla & $161.3 \pm 0.4899$ & 0.68 & $140.7 \pm 1.114$ & 1.77 & $16.97 * * * *$ & $<0.0001$ \\
\hline 39 & Ect - Ent length & $42.72 \pm 0.7189$ & 3.76 & $43.16 \pm 0.364$ & 1.89 & $0.5510 \mathrm{~ns}$ & 0.6018 \\
\hline 40 & External auditory canals distance & $130.6 \pm 0.4179$ & 0.72 & $153.3 \pm 1.715$ & 2.50 & $12.87 * * *$ & 0.0001 \\
\hline 41 & Occipital condyle width & $60.75 \pm 0.4454$ & 1.64 & $72.34 \pm 3.200$ & 9.89 & $3.589 *$ & 0.0216 \\
\hline 42 & Width of jugular apophysis & $82.61 \pm 1.176$ & 3.18 & $88.24 \pm 1.309$ & 3.32 & $3.200 *$ & 0.0128 \\
\hline 43 & Width of occipital hole & $22.70 \pm 0.4648$ & 4.58 & $22.03 \pm 1.169$ & 11.87 & $0.5292 \mathrm{~ns}$ & 0.6183 \\
\hline 44 & Height of occipital hole & $35.97 \pm 0.5103$ & 3.17 & $22.92 \pm 0.667$ & 6.51 & $15.53 * * * *$ & $<0.0001$ \\
\hline 45 & Maximum width of nuchal crests & $79.47 \pm 0.6298$ & 1.77 & $102.6 \pm 0.369$ & 0.81 & $31.68 * * * *$ & $<0.0001$ \\
\hline 46 & Minimum width of nuchal crests & $70.57 \pm 0.4401$ & 1.39 & $95.08 \pm 0.551$ & 1.30 & $34.74 * * * *$ & $<0.0001$ \\
\hline 47 & Aboral height of neurocranium & $135.2 \pm 0.4661$ & 0.77 & $142.7 \pm 1.745$ & 2.73 & $4.146 *$ & 0.0108 \\
\hline 48 & Length of mandible & $327.8 \pm 1.497$ & 1.02 & $277.3 \pm 0.489$ & 0.40 & $32.07 * * * *$ & $<0.0001$ \\
\hline 49 & Height of mandible & $132.8 \pm 2.375$ & 4.00 & $152.3 \pm 0.489$ & 0.72 & $8.042 * * *$ & 0.0009 \\
\hline 50 & Width of mandible branches & $146.5 \pm 0.8138$ & 1.24 & $162.3 \pm 0.489$ & 0.67 & $16.59 * * * *$ & $<0.0001$ \\
\hline 51 & Length of upper canines & $79.30 \pm 0.6633$ & 1.87 & $24.80 \pm 0.374$ & 3.37 & $71.56 * * * *$ & $<0.0001$ \\
\hline 52 & Length of lower canines & $81.30 \pm 0.6633$ & 1.82 & $27.80 \pm 0.378$ & 3.01 & $70.25 * * * *$ & $<0.0001$ \\
\hline
\end{tabular}

Note: ns-insignificant; *-significantly; ${ }^{* *}$-significantly distinct; ***-very significantly; ${ }^{* * * *}$-highly significant 
recorded for skull length, profile length, length of frontal bone, minimum length of the nasal bone, infraorbital hole-P length, the maximum width of the frontal bone, external auditory canals distance and height of mandible.

\section{CONCLUSION}

In the present research work, we conclude based on craniometrical measurements corroborated with statistical data processing the common ancestral origin of the two species, the differences being assigned due to general and special environmental conditions, resulting from the process of domestication.

Acknowledgements. This paper was published under the frame of European Social Fund, Human Resources Development Operational Programme 2007-2013, projectno.POSDRU/159/1.5/S/132765.

\section{REFERENCES}

1. Brudnicki W (2005). Comparison of craniometric features and cranial cavity volume in domestic pig (Sus scrofa forma domestica) and wild boar (Sus scrofa) in view of development. Folia biol., (Kraków) 53 (Suppl.): 25-30.

2. Doychev V, Raychev E, Kostov D (2012). Craniological characteristics of wild boars from the region of Sarnena Sredna Gora Mountain, Bulgaria. Bulg. J. Agric. Sci., 18: 971-979.

3. Genov P, Massei G, Barbalova Z, Kostova V (1992). Aging Wild Boar (Sus scrofa L.) by teeth. Oungules / Ungulates '91, Paris - Toulouse. 399-402.

4. Genov P (1999). A review cranial characteristics in the Wild Boar (Sus scrofa Linnaeus. 1758), with systematic conclusions. Mammal Rev., 29 (4): 205-238.

5. Kozlo P (1975). Dikii kaban, (Wild boar) Urodzaj. Minsk, 1-223 pp. (in Russian).

6. Oberez A (1996). Mandibular molar teeth and the development of mastication in the Miniature Pig (Sus scrofa). Acta. anat., 156: 99-111.

7. Oliver W, Brisbin L, Takahashi S (1993). The Eurasianwild pig (Sus Scrofa). In: Pigs, Peccaries and Hoppos, 112-120. IUCN/SSC, Gland, Switzerland.

8. Von den Driesch A (1976). A Guide to the Measurement of the Animal Bones from Archaeological Sites. Peabody Museum Bulletin1, Harvard University, Massachusetts, 137. 